\title{
Relationship between inflammatory markers, glycated hemoglobin and placental weight on fetal outcomes in women with gestational diabetes
}

Fernanda Oliveira Braga', Carlos Antonio Negrato², Maria de Fátima Bevilacqua da Matta', João Régis Ivar Carneiro³, Marília Brito Gomes ${ }^{1}$
${ }^{1}$ Unidade de Diabetes, Universidade do Estado do Rio de Janeiro (UERJ), Rio de Janeiro, RJ, Brasil ${ }^{2}$ Associação dos Diabéticos de Bauru, Bauru, SP, Brasil ${ }^{3}$ Departamento de Nutrologia, Universidade Federal do Rio de Janeiro (UFRJ), Rio de Janeiro, RJ, Brasil

Correspondence to: Carlos Antonio Negrato Associação dos Diabéticos de Bauru Rua Saint Martin, 27-07 17012-433 - Bauru, SP, Brasil carlosnegrato@uol.com.br

Received on Dec/12/2017 Accepted on Nov/14/2018

DOI: 10.20945/2359-3997000000099

\begin{abstract}
Objective: The aim of this study was to evaluate the relationship between inflammatory cytokines, placental weight, glycated hemoglobin and adverse perinatal outcomes (APOs) in women with gestational diabetes mellitus (GDM). Subjects and methods: This was a prospective, longitudinal and observational study conducted from April 2004 to November 2005 in Bauru, Brazil. Included patients had singleton pregnancies and performed a $100 \mathrm{~g} \mathrm{OGTT}$ and had the levels of C-reactive protein (CRP), interleukin (IL)-6, TNF alfa and glycated hemoglobin (HbA1c) determined at 24-28 th gestation weeks. Results: A total of 176 patients were included, of whom 78 had the diagnosis of GDM (44.3\%). Multivariate analysis demonstrated that $\mathrm{HbA1c}$, age, body mass index (BMI) and previous history of GDM were independent predictors for GDM diagnosis. ROC curve indicated that $\mathrm{HbA} 1 \mathrm{C}$ levels $\geq 5.1 \%$ at $24-28$ weeks gestation were associated with GDM. No difference was found in IL-6, tumor necrosis factor alpha (TNF-alpha) and CRP serum levels in women with and without GDM. Multivariate analysis showed that placental weight was significantly associated with APOs $(p<0.005)$, with a cut-off value of 610 grams as demonstrated by the ROC curve. Conclusion: Placental weight $\geq 610$ grams and $\mathrm{HbA} 1 \mathrm{C} \geq 5.1 \%$ were found to be associated with APOs and GDM, respectively, and their evaluation should be part of prenatal care routine. Arch Endocrinol Metab. 2019;63(1):22-9

Keywords

Gestational diabetes; inflammation; cytokines; placenta; macrosomia; preterm birth
\end{abstract}

\section{INTRODUCTION}

$\mathrm{G}$ estational diabetes mellitus (GDM) is the most I common metabolic disorder found during gestation and is defined as hyperglycemia of variable severity with onset or first recognition during pregnancy that does not clearly characterize any type of preexisting diabetes (1). In Brazil, a study conducted in the 90's called Brazilian Gestational Diabetes Study Group has found that approximately $7.6 \%$ of pregnancies were complicated by GDM (2). In 2010, the International Association of Diabetes and Pregnancy Study Groups has proposed new diagnostic criteria for the diagnosis of GDM with lower cutoff values, which lead to higher diagnostic rates (3). If these criteria were to be used in the population that was evaluated in the Brazilian Gestational Diabetes Study Group, the prevalence of GDM would be $18 \%$ instead of $7.6 \%$ as previously found (4). This finding shows that the prevalence of GDM varies widely depending on the diagnostic criteria that are used (5).
GDM is a heterogeneous disorder, resulting from an interaction between genetic and environmental risk factors. Currently, one of the most important risk factors for the development of GDM is the increasing prevalence of overweight/obesity which is present in up to $60.0 \%$ of women on reproductive age in the USA and some other developed countries (5).

GDM is associated with a constellation of alterations such as impaired insulin secretion, hyperinsulinemia, insulin resistance, obesity, dyslipidemia and hypertension (6), that are related to an increased risk of adverse perinatal outcomes (APOs) such as large for gestational age babies (LGA), overweight (ponderal index) and low Apgar scores (<7) (7).

In general, specific risks of poorly controlled diabetes in pregnancy, that can be evaluated by HbAlc levels, include spontaneous abortion, fetal malformations, preeclampsia, intrauterine fetal demise, macrosomia, neonatal hypoglycemia and neonatal hyperbilirubinemia. Diabetes in pregnancy may increase 
the risk of obesity and type 2 diabetes in the offspring later in life (8).

Placenta is a maternal-fetal organ that separates the maternal and fetal circulations and plays a central metabolic role in pregnancy, mainly in fetal development (9). Several complications found in pregnancy such as GDM, preeclampsia, intrauterine growth restriction, prematurity and low birth weight are linked to angiogenic placental processes that are related to low and high placental weight (10). The human placenta expresses several cytokines including tumor necrosis factor-alpha (TNF-alpha), resistin, C-reactive protein (CRP), interleukin 6 (IL-6) and leptin which are also produced by adipose cells. Cytokines are produced by three different placental cell types: Hofbauer cells, trophoblast cells and vascular endothelium cells. Leptin and IL- 6 are released into the fetal and maternal systemic circulation; they can exert endocrine actions by acting at remote sites from their original production site. In contrast, TNF-alpha is poorly released from placenta and hence is more likely to exert paracrine effects. In GDM, the overexpression of placental TNFalpha is associated with increased fetal adiposity (11).

The aim of this study was to evaluate the relationship between inflammatory markers, placental weight, glycated hemoglobin and APOs in women with GDM.

\section{SUBJECTS AND METHODS}

This was a prospective, longitudinal and observational study conducted between April 2004 and November 2005 in Bauru, a Southeastern Brazilian city. The methodology has been described previously (7). All patients received free health-care from the Brazilian National Health Care System (BNHCS). One hundred and eighty women with singleton pregnancies were invited to participate. In the $3^{\text {rd }}$ trimester $\left(24-28^{\text {th }}\right.$ weeks of gestation) a $100 \mathrm{~g}$ OGTT was performed; the cutoff values for the OGTT were those proposed by Carpenter \& Coustan (12). After performing the test, patients were classified as having GDM if they presented at least two altered values in the curve or controls if they had a normal test (CG).

This study was approved by the ethics committee of Botucatu's School of Medicine - São Paulo State University (Unesp), Brazil. Written informed consent was obtained from all patients.

The following maternal variables were accessed using a questionnaire during a clinical visit: age, parity, ethnicity, years of school attendance, family income (Brazilian minimum wage), weight and length at birth, pre-pregnancy body mass index (BMI), family's history of diabetes, hypertension, obesity and dyslipidemia. At the screening, weight, height, legs length, blood pressure, waist circumference (at the point of minimal abdominal girth) and hip circumference (at the point of maximum extension of the buttocks) were measured. BMI was calculated dividing weight in kilograms by the square of the height in meters. A prepregnancy BMI $\geq 30 \mathrm{~kg} / \mathrm{m}^{2}$ was defined as obesity. When a systolic blood pressure $>$ $140 \mathrm{mmHg}$ or a diastolic blood pressure $>90 \mathrm{mmHg}$ was found on at least two occasions, at least six hours apart, the diagnosis of hypertension was made. The waist-to-hip ratio was calculated dividing waist by hip circumferences.

At the time the OGTT was made, blood samples were collected to determine fasting levels of glucose, HbAlC, total cholesterol, HDL, LDL, VLDL cholesterol and triglycerides. Sera samples were stored at $-80^{\circ} \mathrm{C}$. Glucose oxidase method (Glucose-analyzer II Beckman, Fullerton, CA, USA) was used to determine blood glucose levels. Triglycerides, cholesterol and its fractions (LDL, VLDL, HDL) were measured by enzymatic colorimetric assays. High performance liquid column method (HPLC) was used to determine HbAlC values (Dia-Stat analyzer, Bio-Rad Laboratories, Hercules, CA, USA reference values: 4.0-6.3\%).

The following biochemical parameters were measured: CRP by turbidimetric method (A25 BioSystems and CRP kit BioSystems, with a reference value of $<0.3 \mathrm{mg} / \mathrm{dl}$ and an intra-assay and interassay coefficient of variation of $1.8 \%$ and $3.6 \%$, respectively); IL-6 and TNF-alpha dosages by the MAGPIX (Luminex), multiplex immunoassay (xMAP Technology) with the Human Adipokine Magnetic Bead Panel 2 kit with coefficients of variation for TNFalpha (intra-assay of 3.0\% and inter-assay of $19.0 \%$ ) and for IL-6 (intra-assay of 2.0\% and inter- assay of $10.0 \%$ ).

The following fetal data were collected: birth weight, length, ponderal index, gender, gestational age at delivery, Apgar scores at 1, 2 and 5 minutes, APOs and congenital malformations. Preterm was present when gestational age was $<37$ weeks. The need for a baby to be admitted into an intensive care unit (ICU) was defined by the presence of any acute morbidity. The presence of malformations, respiratory distress syndrome, icterus, infections, LGA, macrosomia, neonatal hypoglycemia and the need to be admitted into an ICU, were considered as APOs. 
Ponderal index was determined by the ratio between 100 times the weight and the cube of the length in $\mathrm{cm}$. Lubchenco's classification was used to determine the relationship between newborns' weight to gestational age (13). Placental weight was obtained immediately after delivery, in the same balance used to evaluate the newborn's weight. Weight was measured in kilograms $(\mathrm{kg})$, grams $(\mathrm{g})$ and in subsequent scales of up to $0.05 \mathrm{~kg}$.

\section{Statistical analysis}

Data are presented as means $( \pm \mathrm{SD})$ or median (minimum-maximum) for continuous variables and numbers (relative frequencies) for discrete variables. Comparisons between independent continuous variables were performed using Mann-Whitney test. Chi-Square $\left(\chi^{2}\right)$ or Fisher tests were used for comparisons between discrete variables. Spearman coefficient of correlation (rho) was performed between clinical and laboratory maternal and fetal data.

Multivariate stepwise forward logistic regression was performed to identify independent demographic and clinical predictors of GDM (yes or no) and for the presence or absence of APOs (LGA, macrosomia, preterm birth, and need for ICU admission). In all models the following parameters were described: coefficient (B), standard error (SE), odds ratio (OR) and 95\% confidence interval (95\% CI). The ROC (receiver operator characteristic) curve was constructed from these analyzes. Analyses were performed using SAS $^{\circledR}$ System, version 6.11 (SAS Institute, Inc., Cary, North Carolina). A two-sided $p$ value less than 0.05 was considered significant.

\section{RESULTS}

\section{Demographic, clinical and laboratory data according to the presence or absence of GDM}

A total of 176 patients were included in the study of whom $78(44.3 \%)$ had the diagnosis of GDM. Four patients were excluded: two were HIV positive and in two blood samples were not adequately stored.

Patients in the GDM group were older, mostly Caucasians $\mathrm{n}=5 \mathrm{l}(65.4 \%)$, had less years of school attendance and lower income. They were also shorter and had shorter legs' length than the CG. They were heavier and presented higher blood pressure levels (both diastolic and systolic). Pregnant women with GDM had a higher frequency of previous history of GDM, higher levels of fasting glucose and HbAlc. These data are described in Tables 1-3.

Table 1. Clinical, demography and laboratory data of the population according to OGTT

\begin{tabular}{|c|c|c|c|c|c|c|c|}
\hline \multirow{2}{*}{ Variable } & \multicolumn{3}{|c|}{ GDM } & \multicolumn{3}{|c|}{ Normal OGTT } & \multirow{2}{*}{ p value ${ }^{a}$} \\
\hline & $\mathbf{N}$ & Median & IQR & $\mathbf{N}$ & Median & IQR & \\
\hline Age (years) & 78 & 31.0 & $29.0-37.0$ & 98 & 27.5 & $24-32$ & $<0.0001$ \\
\hline Education level (years) & 78 & 11.0 & $8.0-12.3$ & 98 & 12.0 & $10.0-15.0$ & 0.004 \\
\hline Family income (Brazilian minimum wage) & 78 & 2.65 & $1.67-7.9$ & 98 & 6.0 & $3.0-12.0$ & 0.0001 \\
\hline Height (m) & 78 & 1.61 & $1.58-1.67$ & 98 & 1.65 & $1.59-1.7$ & 0.010 \\
\hline Legs length (cm) & 78 & 73.3 & $71.0-76.1$ & 98 & 75.0 & $72.5-78.6$ & 0.011 \\
\hline Legs/height ratio (\%) & 78 & 45.6 & $44.5-46.4$ & 98 & 45.8 & $45.0-46.7$ & 0.089 \\
\hline Weight (kg) & 78 & 70.0 & $62.0-87.5$ & 98 & 64.0 & $57.8-72.0$ & 0.0009 \\
\hline Body Mass Index (kg/m²) & 78 & 27.8 & $23.6-32.1$ & 98 & 22.8 & 20.9-27.3 & $<0.0001$ \\
\hline Systolic blood pressure (mmHg) & 78 & 120 & $110-120$ & 98 & 110 & $100-120$ & 0.0001 \\
\hline Diastolic blood pressure (mmHg) & 78 & 80 & $70-80$ & 98 & 70 & $70-80$ & $<0.0001$ \\
\hline Fasting glycemia (mg/dL) & 72 & 90.5 & 82.6-103.3 & 89 & 74.0 & $67.0-79.0$ & $<0.0001$ \\
\hline HbA1c (\%) & 72 & 5.68 & $5.09-6.10$ & 88 & 4.8 & $4.41-5.20$ & $<0.0001$ \\
\hline Total cholesterol (mg/dL) & 72 & 209.0 & $191.0-238.0$ & 89 & 230.0 & $206.0-261.0$ & 0.001 \\
\hline LDL cholesterol (mg/dL) & 70 & 112.0 & $89.0-141.0$ & 89 & 127.0 & $110.0-153.0$ & 0.008 \\
\hline HDL cholesterol (mg/dL) & 72 & 56.3 & $47.6-66.9$ & 89 & 64.0 & $54.3-76.7$ & 0.002 \\
\hline VLDL cholesterol (mg/dL) & 71 & 37.0 & $27.4-44.9$ & 89 & 37.0 & $25.6-48.0$ & 0.90 \\
\hline Triglycerides (mg/dL) & 72 & 185.0 & $132.0-227.0$ & 89 & 185.0 & $128.0-240.0$ & 0.78 \\
\hline IL-6 (pg/mL) & 78 & 0.175 & $0.120-0.298$ & 98 & 0.155 & $0.100-0.325$ & 0.77 \\
\hline $\mathrm{CRP}$ (mg/dL) & 78 & 0.585 & $0.335-1.123$ & 98 & 0.530 & $0.250-0.883$ & 0.40 \\
\hline TNF alpha (pg/mL) & 78 & 0.230 & $0.130-0.330$ & 98 & 0.200 & $0,130-0.310$ & 0.76 \\
\hline
\end{tabular}


Multivariate Analysis according to the presence or absence of GDM

Multivariate logistic analysis performed with 160 observations (missing data of 16 patients for $\mathrm{HbAlc}$ ) showed that HbAlc [OR 4.92; (95\% CI 2.51-9.65); B 1.5931; SE 0.3438, p < 0.0001], age [OR 1.14; (95\% CI 1.06-1.23); B 0.1341; SE 0.0368, $\mathrm{p}=0.0002]$, BMI [OR 1.09; (95\% CI 1.02-1.17); B 0.0880; SE $0.0351, \mathrm{p}=0.012]$ and previous history of GDM [OR 3.73; (95\% CI 1.01-13.8); B 1.3162; SE 0.6669, $\mathrm{p}=$ 0.048 ] were independent predictors of GDM. Figure 1 illustrates the ROC curve of $\mathrm{HbAlc}$ for GDM. An area under the curve (AUC) of 0.79 [95\% CI $(0.72-0.86)$ ] $\mathrm{p}<0.0001)$ was observed. The cut-off value according to the ROC curve for GDM was HbAlc $\geq 5.1 \%$, with a sensitivity of $70.8 \%$ and a specificity of $71.6 \%$.

\section{Clinical and laboratory data, including inflammatory markers and multivariate analysis according to the presence or absence of APOs}

There was no significant difference between the two groups in the levels of the evaluated cytokines, in APOs

Table 2. Previous clinical and obstetric history of the population according to OGT

\begin{tabular}{|c|c|c|c|c|c|c|}
\hline \multirow[b]{2}{*}{ Variable } & \multirow{2}{*}{ Category } & \multicolumn{2}{|c|}{ GDM } & \multicolumn{2}{|c|}{ Normal OGTT } & \multirow{2}{*}{$P$ value } \\
\hline & & $\mathbf{N}$ & $\%$ & $\mathbf{N}$ & $\%$ & \\
\hline \multirow[t]{2}{*}{ Polycystic ovary syndrome } & Yes & 21 & 26.9 & 39 & 39.8 & 0.073 \\
\hline & No & 57 & 73.1 & 59 & 60.2 & \\
\hline \multirow[t]{2}{*}{ Acanthosis } & Yes & 50 & 64.1 & 27 & 27.6 & $<0.0001$ \\
\hline & No & 28 & 35.9 & 71 & 72.4 & \\
\hline \multirow[t]{2}{*}{ Smoking } & Yes & 6 & 7.7 & 7 & 7.1 & 0.15 \\
\hline & No & 72 & 92.3 & 91 & 92.9 & \\
\hline \multirow[t]{2}{*}{ GDM } & Yes & 13 & 16.7 & 6 & 6.1 & 0.025 \\
\hline & No & 65 & 83.3 & 92 & 93.9 & \\
\hline \multirow[t]{2}{*}{ Abortion } & Yes & 21 & 26.9 & 25 & 25.5 & 0.83 \\
\hline & No & 57 & 73.1 & 73 & 74.5 & \\
\hline \multirow[t]{2}{*}{ Stillbirth } & Yes & 3 & 3.8 & 2 & 2.0 & 0.39 \\
\hline & No & 75 & 96.2 & 96 & 98.0 & \\
\hline \multirow[t]{2}{*}{ Babies' mal formation } & Yes & 5 & 6.4 & 3 & 3.1 & 0.24 \\
\hline & No & 73 & 93.6 & 95 & 97.0 & \\
\hline \multirow[t]{2}{*}{ Polyhydramnios } & Yes & 26 & 33.3 & 30 & 30.6 & 0.70 \\
\hline & No & 52 & 66.7 & 68 & 69.4 & \\
\hline \multirow[t]{2}{*}{ Multiple pregnancy } & Yes & 0 & 0.0 & 4 & 4.1 & 0.094 \\
\hline & No & 78 & 100.0 & 94 & 95.9 & \\
\hline \multirow[t]{2}{*}{ Respiratory distress syndrome } & Yes & 5 & 6.4 & 1 & 1.0 & 0.061 \\
\hline & No & 73 & 93.6 & 97 & 99.0 & \\
\hline \multirow[t]{2}{*}{ Preterm birth } & Yes & 13 & 16.7 & 10 & 10.2 & 0.21 \\
\hline & No & 65 & 83.3 & 88 & 89.8 & \\
\hline \multirow[t]{2}{*}{ Neonatal hypoglycemia } & Yes & 0 & 0.0 & 0 & 0.0 & NA \\
\hline & No & 78 & 100.0 & 98 & 100.0 & \\
\hline \multirow[t]{2}{*}{ Icterus } & Yes & 7 & 9.0 & 5 & 5.1 & 0.31 \\
\hline & No & 71 & 91.0 & 93 & 94.9 & \\
\hline \multirow[t]{2}{*}{$<2,500 \mathrm{~g}$ newborn } & Yes & 6 & 7.7 & 7 & 7.1 & 0.89 \\
\hline & No & 72 & 92.3 & 91 & 92.9 & \\
\hline \multirow[t]{2}{*}{$>4,000 \mathrm{~g}$ newborn } & Yes & 9 & 11.5 & 11 & 11.2 & 0.95 \\
\hline & No & 69 & 88.5 & 87 & 88.8 & \\
\hline \multirow[t]{2}{*}{ Pregnancy induced hypertension } & Yes & 12 & 15.4 & 11 & 11.2 & 0.42 \\
\hline & No & 66 & 84.6 & 87 & 88.8 & \\
\hline \multirow[t]{2}{*}{ Newborn death } & Yes & 3 & 3.8 & 0 & 0.0 & 0.085 \\
\hline & No & 75 & 96.2 & 98 & 100.0 & \\
\hline \multirow[t]{2}{*}{ Familial DM } & Yes & 65 & 83.3 & 72 & 73.5 & 0.12 \\
\hline & No & 13 & 16.7 & 26 & 26.5 & \\
\hline
\end{tabular}

OGT: oral glucose tolerance test; GDM: gestational diabetes mellitus; DM: diabetes mellitus.

$\chi^{2}$ test or Fisher test. 
and in placental weight (Tables 1 and 3 ). We observed a correlation between levels of TNF-alpha, maternal BMI and CRP with placental weight $($ rho $=0.188$; $\mathrm{p}=0.021, \mathrm{r}=0.186 ; \mathrm{p}=0.022, \mathrm{r}=0.176 ; \mathrm{p}=0.031$, respectively). A correlation between CRP and HbAlc levels ( $\mathrm{rho}=0.167, \mathrm{p}=0.035)$, in the total sample was also noted. An association between blood glucose [93.2 (76.0-115.4) vs. $79.0(71.0-88.3) \mathrm{mg} / \mathrm{dl} ; \mathrm{p}<0.003]$ and CRP [0.86 (0.68-1.36) mg/dl; p < 0.0l] levels with prematurity was found. A correlation between $\mathrm{CRP}$ and HbAlc levels $(\mathrm{rho}=0.167, \mathrm{p}=0.035)$ in the total sample was also observed.
Multivariate logistic analyses were performed with 150 observations (loss of placental weight records $\mathrm{n}=26$ ) with APOs' as dependent variable. The only significant independent variable was placental weight with an [OR 0.0014; (95\% CI 1.001-1.007; B 1.004; SE $0.0040, \mathrm{p}=0.005]$.

Figure 2 illustrates the ROC curve of placental weight for the presence or absence of APOs. An AUC of 0.65 with a $95 \%$ CI of 0.55 to $0.75,(p=0.003)$ was observed. The cut-off point according to the ROC curve was placental weight $\geq 610$ grams, with a sensitivity of $63.0 \%$ and a specificity of $64.4 \%$.

Table 3. Fetal demographic data according to OGTT

\begin{tabular}{|c|c|c|c|c|c|c|c|}
\hline \multirow{2}{*}{ Variable } & \multicolumn{3}{|c|}{ GDM } & \multicolumn{3}{|c|}{ Normal OGTT } & \multirow{2}{*}{ p value ${ }^{a}$} \\
\hline & $\mathbf{N}$ & Median & IQR & $\mathbf{N}$ & Median & IQR & \\
\hline Newborn weight (grams) & 77 & 3,195 & 2935-3555 & 94 & 3,275 & $2,993-3,564$ & 0.36 \\
\hline Length (cm) & 77 & 48.0 & $46.5-49.0$ & 94 & 48.5 & $47.0-50.0$ & 0.18 \\
\hline Head circumference (cm) & 76 & 35.0 & $33.5-35.0$ & 93 & 35.0 & $34.0-36.0$ & 0.24 \\
\hline Thoracic circumference (cm) & 76 & 33.0 & $32.0-34.0$ & 93 & 33.2 & $32.0-34.0$ & 0.96 \\
\hline Waist circumference (cm) & 73 & 32.0 & $30.0-33.0$ & 78 & 32.0 & $30.0-33.0$ & 0.72 \\
\hline Apgar T1 score & 77 & 9 & $8-9$ & 93 & 9 & $8-9$ & 0.68 \\
\hline Apgar T2 score & 77 & 10 & $9-10$ & 93 & 10 & $9-10$ & 0.92 \\
\hline Apgar T5 score & 77 & 10 & $10-10$ & 93 & 10 & $10-10$ & 0.52 \\
\hline Placental weight (grams) & 72 & 600 & $500-684$ & 78 & 580 & $518-713$ & 0.65 \\
\hline
\end{tabular}

IQR: interquartile range; GDM: gestational diabetes mellitus; OGTT: oral glucose tolerance test. a Mann-Whitney test.

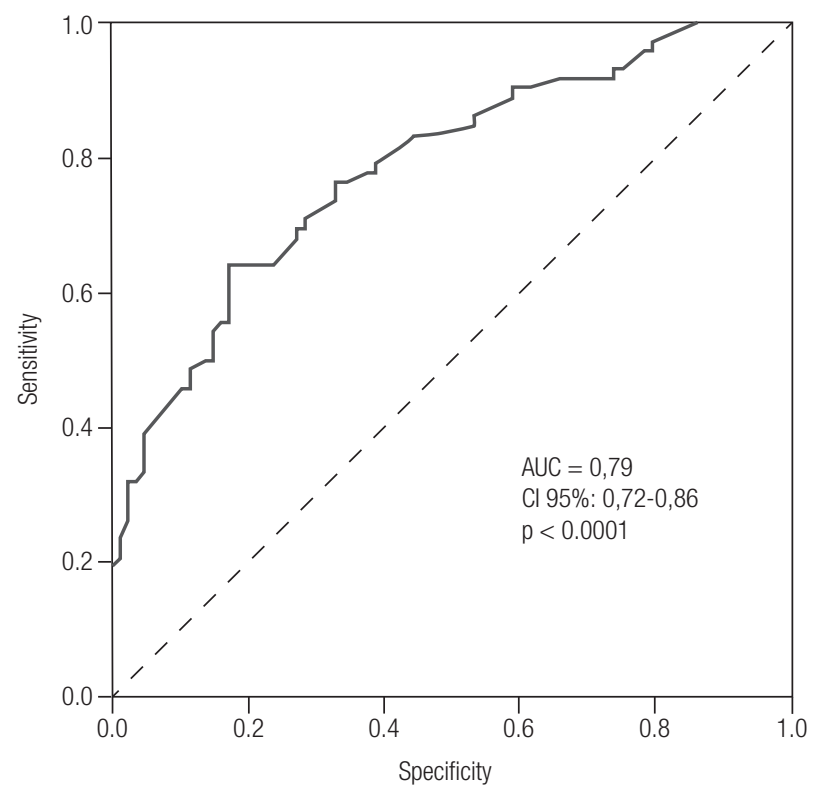

Figure 1. ROC curve for $\mathrm{HbA1C}$ as a predictor for GDM.

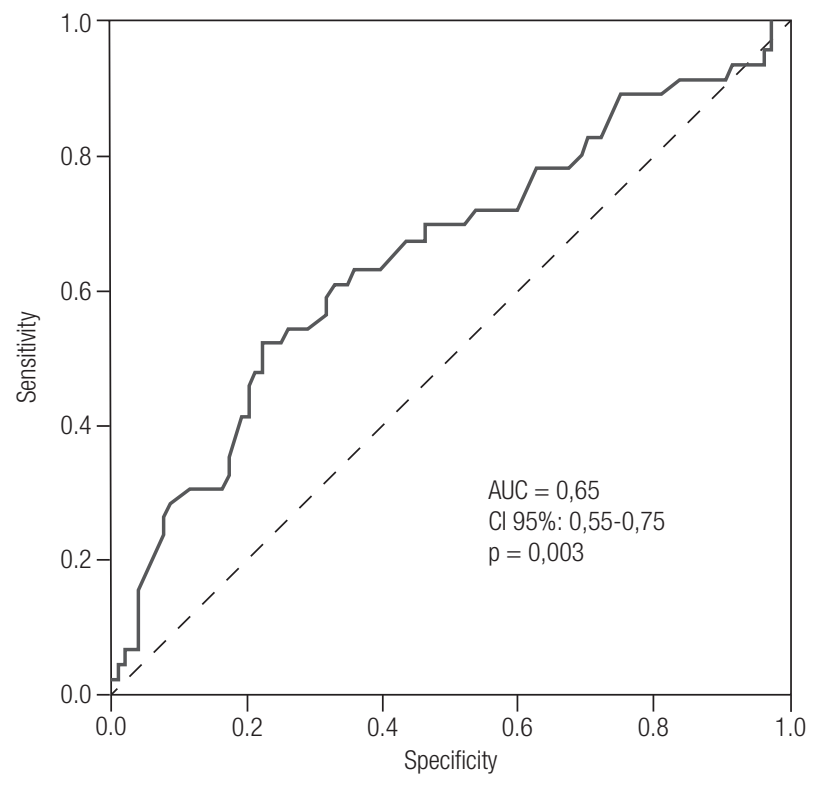

Figure 2. Receiver Operator Characteristics (ROC) curve for placental weight as a predictor of fetal adverse outcomes. 


\section{DISCUSSION}

No difference was found in serum levels of IL-6, TNF-alpha, CRP and placental weight in women with GDM compared to those from the CG, between 2428 gestation weeks. We found that values of $\mathrm{HbAlC} \geq$ $5.1 \%$ at 24 to 28 weeks of gestation could be associated with GDM, however with high sensitivity and low specificity. A placental weight $\geq 610$ grams was also found to be associated with the presence of APOs.

Our prevalence of GDM was higher than the prevalence found in the Brazilian Study on Gestational Diabetes (BSGD) in the 1990s, which was 7.6\% (2). This may be justified by the fact that our study was performed at a secondary level medical care service, focused on diabetes in pregnancy, and also by the increasing prevalence of overweight and obesity in Brazil in recent years. In 1999, around the time this study begun, the estimated prevalence of obesity in the Brazilian general population was of $32.0 \%$ (14) and has been steadily increasing ever since, reaching $53.8 \%$ in 2016 (15). It is possible that if these data were to be collected nowadays, the rates of GDM would be even greater.

In our study, pregnant women with GDM were older, shorter, heavier, with higher blood pressure levels and shorter legs $(16,17)$ as expected, since all these characteristics are risk factors for the development of GDM (18).

Multivariate analysis for the prediction of GDM demonstrated that HbAlc, age, BMI and previous history of GDM were independently associated with GDM. The ROC curve indicated that values of $\mathrm{HbAlC}$ $\geq 5.1 \%$ at 24 to 28 gestation weeks are associated with GDM.

Universal screening for diabetes in pregnancy is recommended by the International Association of the Diabetes and Pregnancy Study Groups (IADPSG) (3), the American Diabetes Association (ADA) (1) the World Health Organization (WHO) (19) and more recently by the Brazilian Diabetes Association (BDS), Brazilian Federation of Gynecologists and Obstetricians (Febrasgo), Pan American Health Organization (PAHO) and the Brazilian Ministry of Health at the first antenatal visit (20). However what should be the most appropriate test and glucose levels thresholds are still debated in many regions and countries around the world $(21,22)$. This screening should be done with a fasting glycemia and a $75 \mathrm{~g}$ OGTT at the first antenatal visit or at 24-28 gestation weeks, respectively (20).
The OGTT is time consuming, poorly tolerated by pregnant women, needs a previous patient preparation and presents issues with preanalytical stability and reproducibility $(21,22)$. HbAlc, the most used measurement of chronic glycemia outside of pregnancy is easier to perform, does not need a previous patient preparation and is much less time consuming than the OGTT. However, the evaluation of HbAlc has its limitations such as: conditions that promote a reduction in the real value of HbAlc due to the reduction in the number of red blood cells, hemoglobin levels and hematocrit, conditions that increase the real value of HbAlc (2l) and the period of pregnancy in which it is performed, being lower in the first trimester and around $0.5 \%$ lower at the $14^{\text {th }}$ week $(22)$.

However it is important to emphasize that the accuracy of HbAlc as a screening tool in pregnancy has been studied in recent decades and the results are inconsistent (22-29). Thus, it would be necessary to establish reference values according to different ethnic populations before recommending the universal use of HbAlc for the screening of GDM (28). Khalafallah and cols. (2l) aiming to compare HbAlc levels with glucose values on the $75 \mathrm{~g}$ OGTT for the screening and diagnosis of GDM, found a HbAlc cut-off point of $5.4 \%$ associated with GDM, with a negative predictive value of $91.0 \%$ and a specificity of $95.0 \%$. Similar results were also obtained when a cut-off point of HbAlc > $5.1 \%$ was used, with a sensitivity of $55 \%$ and a specificity of $80.0 \%$, which was also the cut-off point we found (21). In our study, the cut- off point of $\mathrm{HbAlc}>5.1 \%$ had higher sensitivity $(70.9 \%)$ and lower specificity $(71.6 \%)$ than this study.

Studies with small number of patients revealed an increase in inflammatory markers such as TNF-alpha (30) and CRP (31) in women with GDM which was not found in our study, maybe because the prevalence of obesity was small among those patients. In a study conducted in Austria, evaluating women with and without GDM an increase in CRP levels in pregnant women with GDM was found only at $37^{\text {th }}-38^{\text {th }}$ weeks gestation but not at $24^{\text {th }}-28^{\text {th }}$ weeks $(32)$, the time frame we conducted our study. Cytokine levels fluctuate during the gestational trimesters, being the first and third trimesters characterized by a pro-inflammatory state and the second trimester by an anti-inflammatory state.

There was a correlation between TNF-alpha values, maternal BMI and CRP levels with placental weight 
in our study. This correlation, although weak (rho < 0.30 ), can point to a relationship between BMI with TNF-alpha and CRP that can generate damage to the placenta due to their inflammatory actions independent of glycemic levels. Retnakaran and cols. (31) performed a study with 180 healthy pregnant women who underwent an OGTT at the end of the $2^{\text {nd }}$ and beginning of the $3^{\text {rd }}$ trimester and found higher CRP levels in patients with normal OGTT and overweight and a correlation between CRP and prepregnancy BMI.

In our study, placental weight was an independent predictor for the presence of any of the following APOs (LGA, macrosomia, preterm birth and need for neonatal ICU admission) with a cut-off point of $\geq 6 \mathrm{l} 0 \mathrm{~g}$. Studies performed with pregnant women having GDM indicate that they could have greater placental weight in relation to pregnant women having $\operatorname{GDM}(33,34)$, which we did not find in our study. In a study performed in Tanzania (35), in Sub-Saharan Africa, with 6,579 pregnant women, younger and with lower BMI than those patients enrolled in our study, low placental weight was associated with an increased risk of APOs. Possibly, a poorer nutritional status and the presence of infectious diseases in that population could have contributed for these results. Disruptions in placental growth can have long-term consequences on perinatal and childhood health and have been associated with adverse obstetric outcomes (intrauterine growth restriction and preeclampsia, maternal disease), perinatal mortality and morbidity, as well as impairment in childhood growth and development $(10,35)$. A Romanian study (33), with pregnant women between 24-28 weeks of gestation showed that the placentas of six out of 13 GDM patients presented micro and macroscopic alterations. Macroscopically, the most frequent pathological changes found were larger placental size, volume and weight. It was also observed that, in the total sample, the presence of preterm birth was related to higher levels of fasting glycemia and CRP. The Camden Study conducted in USA, including 520 pregnant women with normal OGTT, showed that during pregnancy, higher levels of CRP were related to APOs, such as prematurity, only in lean women (BMI $<25)(36)$.

Some limitations of this study must be addressed such as the small number of patients and also the pregestational weight that was self-reported by the patients, which could generate some "bias". We also correlated the presence of one or more APOs among those that were evaluated, with placental weight; therefore, we do not know which outcome had the greatest statistical strength this correlation.

In conclusion, in our study, some predictors of GDM are modifiable such as high BMIs and HbAlc levels. HbAlc values $\geq 5.1 \%$ at $24-28$ weeks gestation were found to be associated with GDM, but we cannot hypothesize that this test could be used as a tool for GDM screening or diagnosis, because in our study, the sensitivity and specificity were low. A placental weight $\geq$ 610 grams was found to be associated with APOs, and consequently its weight should be monitored through ultrasound evaluation during the whole pregnancy as part of prenatal care routine to stratify risks for APOs. Further prospective studies with larger number of participants are necessary to confirm if this placental cutoff weight is associated to APOs for all pregnant women or just for those with GDM.

Acknowledgements: we thank all members of our work teams in our units that enabled us to dedicate ourselves to this research.

Funding source: this research was supported by "Fundação do Amparo à Pesquisa do Estado do Rio de Janeiro" (Faperj).

Disclosure: no potential conflict of interest relevant to this article was reported.

\section{REFERENCES}

1. American Diabetes Association. Classification and Diagnosis of Diabetes. Standards of medical Care in Diabetes - 2017. Diabetes Care. 2017;40(Suppl 1):S18.

2. Schmidt MI, Matos MC, Reichelt AJ, Forti AC, de Lima L, Duncan BB. Prevalence of gestational diabetes mellitus - do the new WHO criteria make a difference? Brazilian Gestational Diabetes Study Group. Diabet Med. 2000;17(5):376-80.

3. International Association of Diabetes and Pregnancy Study Groups Consensus Panel; Metzger BE, Gabbe SG, Persson B, Buchanan TA, Catalano PA, Damm P, et al. International Association of Diabetes and Pregnancy Study Groups recommendations on the diagnosis and classification of hyperglycemia in pregnancy. Diabetes Care. 2010;33(3):676-82.

4. Trujillo J, Vigo A, Duncan BB, Falavigna M, Wendland EM, Campos MA, et al. Impact of the International Association of Diabetes and Pregnancy Study Groups criteria for gestational diabetes. Diabetes Res Clin Pract. 2015;108(2):288-95.

5. Koivusalo SB, Rönö K, Klemetti MM, Roine RP, Lindström J, Erkkola M, et al. Gestational Diabetes Mellitus Can Be Prevented by Lifestyle Intervention: The Finnish Gestational Diabetes Prevention Study (RADIEL): A Randomized Controlled Trial. Diabetes Care. 2016;39(1):24-30.

6. Clark CM Jr, Qiu C, Amerman B, Porter B, Fineberg N, Aldasouqi $\mathrm{S}$, et al. Gestational diabetes: should it be added to the syndrome of insulin resistance? Diabetes Care. 1997;20(5):867-71.

7. Negrato CA, Jovanovic L, Tambascia MA, Calderon Ide M, Geloneze $B$, Dias $A$, et al. Mild gestational hyperglycaemia as a risk 
factor for metabolic syndrome in pregnancy and adverse prenatal outcomes. Diabetes Metab Res Rev. 2008;24:324-30.

8. American Diabetes Association. Management of diabetes in pregnancy. Sec.12. In Standards of Medical Care in Diabetes-2016. Diabetes Care. 2016;39(Suppl 1):S94-8.

9. Rudge MV, Lima CP, Damasceno DC, SinzatoYK, Napoli G, Rudge $\mathrm{CV}$, et al. Histopathological placental lesions in mild gestational hyperglycemic and diabetic women. Diabetol Metab Syndr. 2011;10;3(1):19.

10. McNamara H, Hutcheon JA, Platt RW, Benjamin A, Kramer MS. Risk factors for high and low placental weight. Paediatr Perinat Epidemiol. 2014;28(2):97-105.

11. Desoye G, Hauguel-de Mouzon S. The human placenta in gestational diabetes mellitus. The insulin and cytokine network. Diabetes Care. 2007;30 Suppl 2:S120-6.

12. Carpenter MW, Coustan DR. Criteria for screening tests for gestational diabetes. Am J Obstet Gynecol. 1982;144(7):768-73.

13. Lubchenco LO, Hansman C, Boyd E. Intrauterine growth in length and head circumference as estimated from live births at gestational ages from 26 to 42 weeks. Pediatrics. 1966;37(3): 403-8.

14. Sociedade Brasileira de Cardiologia. Exercício anti-sedentarismo/ obesidade. 1999. Available at: http://www.cardiol.br/exerc.htm. Acessed in: 13 Feb 2017].

15. Vigitel .2016. Available at: https://www.endocrino.org.br/media/ uploads/PDFs/vigitel/pdf. Acessed in: 23 Apr 2017).

16. Moses RG, Mackay MT. Gestational Diabetes: is there a relationship between leg length and glucose tolerance? Diabetes Care. 2004;27(5):1033-5.

17. Ma RM, Lao TT, Ma CL, Liao SJ, Lu YF, Du MY, et al. Relationship between leg length and gestational diabetes mellitus in Chinese pregnant women. Diabetes Care. 2007;30(11):2960-1.

18. Ben-Haroush A, Yogev $Y$, Hod M. Epidemiology of gestational diabetes mellitus and its association with type 2 diabetes. Diabet Med. 2004;21(2):103-13.

19. World Health Organization. Diagnostic criteria and classification of hyperglycaemia first detected in pregnancy. 2013. Available at: http://www.who.int/diabetes/publications/Hyperglycaemia_In_ Pregnancy/en/. Accessed 23 May 2016.

20. Organização Pan-Americana de Saúde. Ministério da Saúde. Federação Brasileira das Associações de Ginecologia e Obstetrícia. Sociedade Brasileira de diabetes. Rastreamento e diagnóstico de diabetes mellitus gestacional no Brasil. Brasília, DF: OPAS; 2016.

21. Khalafallah A, Phuah E, AI-Barazan AM, Nikakis I, Radford A, Clarkson W, et al. Glycosylated haemoglobin for screening and diagnosis of gestational diabetes mellitus. BMJ Open. 2016;6(4):e011059.

22. Hughes RC, Moore MP, Gullam JE, Mohamed K, Rowan J. An early pregnancy $\mathrm{HbA} 1 \mathrm{c} \geq 5.9 \%(41 \mathrm{mmol} / \mathrm{mol})$ is optimal for detect- ing diabetes and identifies women at increased risk of adverse pregnancy outcomes. Diabetes Care. 2014;37(11):2953-9.

23. Agarwal MM, Hughes PF, Punnose J, Ezimokhai M, Thomas L. Gestational diabetes screening of a multiethnic, high-risk population using glycated proteins. Diabetes Res Clin Pract. 2001;51(1):67-73.

24. Agarwal MM, Dhatt GS, Punnose J, Koster G. Gestational diabetes: a reappraisal of HBA1c as a screening test. Acta Obstet Gynecol Scand. 2005;84(12):1159-63.

25. Pollak A, Brehm R, Havelec L, Lubec G, Malamitsi-Puchner A, Simbrunner G, et al. Total glycosylated hemoglobin in mothers of large-for-gestational-age infants: a postpartum test for undetected maternal diabetes? Biol Neonate. 1981;40(3-4):129-35.

26. Griffiths RJ, Vinall PS, Stickland MH, Wales JK. Haemoglobin A1c levels in normal and diabetic pregnancies. Eur J Obstet Gynecol Reprod Biol. 1987;24(3):195-200.

27. Moses RG. HbA1c and the diagnosis of gestational diabetes mellitus - a test whose time has not yet come. Diabetes Res Clin Pract. 2012;98:3-4.

28. Lippi G, Targher G. Glycated hemoglobin ( $\mathrm{HbA1c}$ ): old dogmas, a new perspective? Clin Chem Lab Med. 2010;48(5):609-14.

29. Netto AP. Grupo Interdisciplinar de Padronização da Hemoglobina Glicada in Atualização sobre Hemoglobina Glicada para avaliação do controle glicêmico e para o diagnóstico do Diabetes Mellitus: aspectos clínicos e laboratoriais. J Bras Patol Med Lab. 2009;45(1):31-48.

30. Winkler G, Cseh K, Baranyi E, Melczer Z, Speer G, Hajós P, et al. Tumor necrosis factor system in insulin resistance in gestational diabetes. Diabetes Res Clin Pract. 2002;56(2):93-9.

31. Retnakaran R, Hanley AJ, Raif N, Connelly PW, Sermer M, Zinman B. C-Reactive Protein and Gestational Diabetes: The Central Role of Maternal Obesity. J Clin Endocrinol Metab. 2003;88(8):3507-12.

32. Leipold H1, Worda C, Gruber CJ, Prikoszovich T, Wagner O, Kautzky-Willer A. Gestational diabetes mellitus is associated with increased $\mathrm{C}$-reactive protein concentrations in the third but not second trimester. Eur J Clin Invest. 2005;35(12):752-7.

33. Edu A, Teodorescu C, Dobjanschi CG, Socol ZZ, Teodorescu V, Matei $A$, et al. Placenta changes in pregnancy with gestational diabetes. Rom J Morphol Embryol. 2016;57(2):507-12.

34. Taricco, E, Radaelli, T, Nobile de Santis, MS, Cetin, I. Foetal and placental weights in relation to maternal characteristics in Gestational Diabetes. Placenta. 2003;24(4):343-7.

35. McDonald CR, Darling AM, Liu E, Tran V, Cabrera A, Aboud $S$, et al. Angiogenic proteins, placental weight and perinatal outcomes among pregnant women in Tanzania. PLoS One. 2016;9;11(12):e0167716.

36. SchollTO, Chen X, Goldberg GS, Khusial R, Stein P. Maternal Diet, C-Reactive Protein, and the Outcome of Pregnancy. J Am Coll Nutr. 2011;30(4):233-40. 